\title{
Problemas Metodológicos em CiênCiAs da ReligiÃo: uma estranha familiaridade
}

\author{
METHODOLOGICAL PROBLEMS IN RELIGION SCIENCES: \\ a strange familiarity
}

\author{
Mailson Fernandes Cabral de Souza*
}

\begin{abstract}
RESUMO
O presente artigo tem por objetivo analisar a constituição e circulação de sentidos dos discursos que versam sobre a metodologia das Ciências da Religião no Brasil. Para isso, foram selecionados para compor o corpus dois artigos que discutem a questão metodológica da área. O marco teórico-analítico da pesquisa foi o da Análise de Discurso de linha francesa, a partir de sua interface com a história das ciências. Os principais conceitos utilizados foram os de formação discursiva, interdiscurso, pré-construído e discurso transverso. Como resultado, pudemos observar como os textos analisados silenciam os discursos que constituíram a história da área no país. Em razão disso, defendemos que o entendimento das condições de produção das Ciências da Religião no contexto brasileiro é necessário para compreender e melhor situar os impasses epistemológicos que lhes são pertinentes.
\end{abstract}

Palavras-chave: Discurso Científico. Epistemologia. Método.

\section{ABSTRACT}

This papers aims to analyze the constitution and circulation of meanings of the discourses that deal with a methodology of the Sciences of Religion in Brazil. For this, two papers were selected to compose the corpus that discuss about the methodological question of the area. The theoretical-analytical framework of the research was the Discourse Analysis of french line, from its interface with the history of the sciences. The main concepts used were discursive formation, interdiscourse, pre-built and transverse discourse. As a result, we could observe how the analyzed texts silenced the discourses that constituted the history of the area in the country. For this reason, we defend that the understanding of the conditions of production of the Sciences of Religion in the Brazilian context is necessary to understand and better situate the epistemological impasses that are relevant to them.

Keywords: Scientific Discourse. Epistemology. Method.

\section{INTRODUÇÃO}

As Ciências da Religião se configuram como um campo de estudos que, surgido no contexto brasileiro no final dos anos 1960, tem-se expandido fortemente desde o início dos anos 2000. Na área, as interfaces das ciências humanas (História, Antropologia, Psicologia, Sociologia, Filosofia, etc.) são mobilizadas para a análise do fenômeno religioso, a fim de se obter uma abordagem multidimensional da religião.

\footnotetext{
* Mestre em Ciências da Religião pela Universidade Católica de Pernambuco e membro do Observatório Transdisciplinar das Religiões no Recife, também na mesma instituição. E-mail: mailsoncabral@yahoo.com.br
} 
Além disso, as Ciências da Religião representam também o campo do saber responsável por fornecer os conteúdos pedagógicos para o ensino religioso não confessional na rede de escolas públicas do país.

Diante da importância que esse campo tem adquirido, diferentes discursos têm disputado o seu estatuto epistemológico, em especial, no que tange à sua metodologia. Isso ocorre em função de entendimentos divergentes sobre qual seria a paternidade teórica das Ciências da Religião no Brasil, silenciando-se, nesse processo, os referentes históricos constituintes da área. A fim de demonstrar isso, selecionamos como corpus dois artigos (SILVEIRA, 2016; STERN; COSTA, 2017) que tratam da questão metodológica na atualidade.

Nesse sentido, duas questões são norteadoras para o desenvolvimento de nossa investigação: as Ciências da Religião surgem como um desenvolvimento do trabalho de pesquisadores brasileiros ou como algo importado para o país? Que filiações teóricas lhe caracterizam? O trabalho está dividido em seis momentos além da presente introdução: a) o debate epistemológico; b) contextualização histórica da área c) apresentação do arcabouço teórico-metodológico de pesquisa; d) delineamento metodológico adotado no tratamento do corpus e) análise discursiva do corpus selecionado; f) alguns encaminhamentos e contribuições para esse debate a partir de nosso estudo.

\section{PROBLEMAS IDENTITÁRIOS}

Desde o começo dos anos 2000 vem se configurando, no Brasil, a discussão acerca dos métodos, objeto e teorias que seriam próprias ao campo das Ciências da Religião (doravante $\mathrm{CR}$ ). $\mathrm{O}$ primeiro resultado desse trabalho foi o livro $A(s)$ Ciência(s) da Religião no Brasil, organizado por Faustino Teixeira, publicado em 2001. A obra foi fruto de um seminário ocorrido na Universidade Federal de Juiz de Fora, em outubro de 2000. Nele, alguns dos principais pesquisadores das CR discutiram a questão da afirmação acadêmica da área no país, resultando nos textos que compõem o livro. 
A partir de então, uma série de publicações ${ }^{1}$ tem trazido essa discussão à baila, evidenciando a sua importância. Fazendo um traçado a partir da própria nomenclatura da área, podemos destacar ao menos três tendências teóricas que orientam o debate, visto que elas são um indicativo que remete às compreensões que os pesquisadores possuem acerca da epistemologia: 1) Ciência da Religião: parte-se da ideia de que ela se trata de uma ciência autônoma que tem o seu objeto e métodos próprios (GRESCHAT, 2005; USARSKI, 2006); 2) Ciências da Religião: supõe-se que o estudo do objeto religião deva partir de um conjunto de disciplinas (Filosofia, Ciências Sociais da Religião, Psicologia, História etc.), configurando a área como de enfoque interdisciplinar ou transdisciplinar (CAMURÇA, 2008; ARAGÃO, 2015); 3) Ciências das Religiões: designaria uma área multidisciplinar que tem como objeto as diferentes religiões, não havendo um fenômeno singular denominado religião, mas diferentes religiões que devem ser consideradas a partir de suas particularidades (FILORAMO; PRANDI, 1999). No caso brasileiro, a nomenclatura mais comumente utilizada pelos programas de pós-graduação e adotada pela Coordenação de Aperfeiçoamento de Pessoal de Nível Superior (CAPES), órgão governamental que regula o funcionamento das pós-graduações no país, é a de Ciências da Religião², sendo compreendida como uma área interdisciplinar.

Em nosso entendimento, esse impasse é um indicativo do que Portella (2011) denominou de incerteza identitária. Ela seria o resultado de compreensões

\footnotetext{
${ }^{1}$ Há um interessante conjunto de entrevistas feitas por Marques e Rocha (2007) com alguns dos primeiros professores da área no Brasil; uma seção temática da Revista Numen, publicada em 2012, com diversos artigos que tratam sobre a história dos principais programas de CR; dois dossiês organizados pela Revista Paralleus, um em 2015 e outro em 2016, dedicados às técnicas, métodos e tendências de pesquisa em CR; uma edição da Revista Sacrilegens, em 2017, com alguns de seus artigos dedicados à epistemologia. Há também vários artigos publicados de forma dispersa, dos quais destacamos os de Usarki (2004); Portella (2011); Camurça (2011); Aragão (2015) e Senra (2015). Destacamos uma série de livros que se dedicam à questão, como os da Coleção "Repensando a Religião" lançada pela Editora Paulinas e dirigida por Afonso Ligório Soares: O que é Ciência da Religião? (GRESHAT, 2005), Constituintes da Ciência da Religião: cinco ensaios em prol de uma disciplina autônoma (USARSKI, 2006), O espectro disciplinar da Ciência da Religião, (USARSKI, 2007), Ciências Sociais e Ciências da Religião: polêmicas e interlocuções (CAMURÇA, 2008), Uma Teoria da Religião (STARK; BAINBRIDGE, 2008). Fruto de um esforço coletivo para pensar as diferentes interfaces da área, tendo todo um capítulo dedicado às questões epistemológicas, é $\mathrm{O}$ Compêndio de Ciência da Religião (PASSOS; USARSKI, 2013). Recentemente foi lançado A Dimensão Teórica dos Estudos da Religião: horizontes histórico, epistemológico e metodológico nas Ciências da Religião (SILVEIRA; MORAES, 2017). Existem alguns capítulos em outras obras que também tratam da questão - ver Gross (2012) e Pieper (2017). A nossa pretensão não é fazer uma lista exaustiva de referências bibliográficas sobre o tema, mas mostrar que esse debate, embora ainda não ocupe um lugar central nas CR, sempre retorna como pauta.

2 Será essa a nomenclatura adotada em nosso estudo, tanto por ela ser a mais utilizada como por entendermos que a área surge, no Brasil, sob um prisma interdisciplinar.
} 
divergentes sobre o que seja a área e da ausência de um consenso mínimo que estabeleça as bases comuns de um projeto acadêmico para as CR no Brasil. Não há um acordo de como as noções de ciência(s) e de religião(ões) são entendidas, estando o conflito entre unidade e pluralidade marcado na própria maneira em que a área é denominada. Essa divergência é expressa pela fragmentação identitária dos pesquisadores formados em CR:

A disciplina ciência da religião é encarada como um agregado de disciplinas, o que ela de certo modo é; o mestre em ciência da religião, quando sai, sente-se competente como sociólogo da religião etc., mas não como cientista da religião enquanto tal (DREHER, 2001, p. 171 [grifos do autor]).

Isso ocorre porque as CR não funcionam, na prática, nem como campo interdisciplinar nem como disciplina, porém como uma câmara em que as diversas disciplinas das ciências humanas e sociais que versam sobre a temática religião se abrigam sem, no entanto, haver um deslocamento dessas disciplinas para a constituição de um campo do saber. Em razão disso, o que se pode observar são diferentes posições que se inscrevem ideologicamente a outras disciplinas e, consequentemente, reproduzem os procedimentos teórico-metodológicos de suas respectivas áreas de origem.

Nosso argumento é o de que tal fragmentação está ligada ao fator histórico de institucionalização das CR no país, sendo uma questão anterior ao debate sobre o seu estatuto epistemológico. Embora trabalhos recentes procurem estabelecer um elo entre as CR feitas no Brasil e as tradições alemã e anglófona (PIEPER, 2017; STERN; COSTA, 2017), que têm mais de um século e meio de existência, o caso brasileiro difere substancialmente em sua gênese das tradições internacionais porque surge como um desdobramento da Teologia da Libertação. A fim de melhor elucidar o que dizemos, cumpre fazer uma digressão histórica para entender o problema.

\section{UM REDEMOINHO DE MEMÓRIAS: AS CR NO BRASIL}

Os textos que se ocupam em relatar o nascimento dos primeiros programas de pós-graduação em CR no país - Pontifícia Universidade Católica de São Paulo (PUCSP), Universidade Metodista de São Paulo (UMESP) e Universidade Federal de Juiz 
de Fora (UFJF) -, que ocorreram entre o final dos anos de $1960^{3}$ e início dos anos 1990, convergem na afirmação de que área surge sob a forte influência da Teologia da Libertação e do movimento ecumênico, então em voga no contexto latino-americano (TEIXEIRA, 2012; MENDONÇA, 2004; MARQUES; ROCHA, 2007). O intuito, nesse período, era o de "dar um estatuto científico e uma identidade aos estudos da religião no quadro das Ciências Humanas no Brasil" (VALLE, 2007 apud MARQUES; ROCHA, 2007, p. 196). Assim, a gênese da área se liga a forma que teólogos e acadêmicos, oriundos de outros campos das ciências humanas, pensavam o fenômeno religioso: o de estudá-lo fora do âmbito da teologia tradicional e o de trazêlo para a universidade brasileira que, dada a influência do positivismo, teria excluído o fenômeno religioso do centro de suas discussões e pesquisas4. A influência teológica, focada nos problemas sociais, não era tida como um problema, porém como uma forma articulada de pensar a religião:

[...] nós usávamos um referencial predominante. Era o mesmo referencial teológico da nossa Teologia latino-americana, uma análise dialética da religião e uma análise dialética da sociedade. Existia, então, uma articulação importante. Não havia, portanto, o pensamento de que deveríamos nos separar da Teologia porque ela segue por um viés e nós vamos por outro, não havia essa discussão. O que existia, sim, era um bom senso de enfoque (QUEIROZ, 2007 apud MARQUES; ROCHA, 2007, p. 206).

Diante desse quadro, é possível elencar, segundo Valle (2007) apud Marques e Rocha (2007), ao menos três fatores que teriam motivado a criação dos cursos de CR: a) o sentimento de que o estudo da religião se encontrava fragmentado e, portanto, havia uma urgência em unificá-lo; b) o intuito de reunir os pesquisadores e professores das diferentes disciplinas das ciências humanas a fim de produzir uma interlocução entre eles, visto que, a priori, eles compartilhariam uma temática

\footnotetext{
3 Em 1969 é criado o colegiado de Ciências das Religiões, na UFJF sob a direção de Jaime Snoek. Em 1970, É fundado o departamento de CR, chegando a ser realizado um vestibular para a sua primeira turma de graduação. Porém, o curso foi interrompido antes da conclusão da primeira turma, embora o departamento continuasse existindo na universidade, vindo somente a retornar em 1993, como programa de pós-graduação (TEIXEIRA, 2012). O primeiro programa de pós-graduação efetivamente de CR é o da PUC- SP, em 1978, e, na sequência, o da UMESP, em 1979. São esses programas que formam a memória inicial da institucionalização da área no Brasil.

4 Algumas exceções podem ser apontadas como, por exemplo, a chegada, em meados da década de 1930, de Roger Bastide e Lévi-Strauss, pesquisadores franceses do campo das ciências sociais interessados no fenômeno religioso brasileiro, na recém fundada Universidade de São Paulo (USP) na qual assumiram cátedra. Nesse sentido, a USP seria o primeiro espaço a concentrar os estudos sociais da religião no país.
} 
comum que os ligava; c) a evolução do fenômeno religioso brasileiro que, de uma forte hegemonia católica, tornou-se um cenário multifacetado de religiões, principalmente após a segunda metade do século XX.

Apesar disso, o que aqui se desenvolve não é um projeto ordenado e progressivo das CR, com uma proposta teórico-analítica do estudo da religião, mas algo marcado pelas contingências históricas e políticas. Não havia uma ideia nuclear do que fosse o campo que então se perfilava:

Parece não ter havido nenhuma idéia a não ser a ditada pelas circunstâncias. Nenhum debate ou estudo que pusesse em relevo questões de ordem científica em favor das Ciências da Religião. $O$ que houve foi um salto histórico na apropriação de um estágio avançado da questão já em uso na Europa. Houve entre nós a tentativa de superação abrupta de uma tradição arcaica, marcada pela dupla presença de dois fatores antagônicos que imobilizavam qualquer pretensão de considerar a religião como objeto de ciência: a Teologia metafísica com seus absolutos universais, de um lado, e o Positivismo que se batia pela superação desse estágio como empecilho do progresso científico, de outro. A falta de uma fundamentação inicial iria provocar depois de alguns anos um debate que ainda se prolonga (MENDONÇA, 2007, apud MARQUES; ROCHA, 2007, p. 208-209 [grifos nossos]).

Em síntese, a área surge muito mais como um desenvolvimento dos estudos e do engajamento político de pesquisadores brasileiros do que como algo importado de outro país ou tradição, o que, por sua vez, não exclui a influência estrangeira5, contudo, evidencia que a organização e tratamento das questões que orientavam o trabalho no Brasil eram distintos. Foi no campo das Ciências Sociais que as CR encontraram o seu grande ponto de apoio para as primeiras reflexões e pesquisas. Assim, os estudos de religião ocorreram, no país, por meio de um modelo de complementaridade e de aliança entre a Teologia da Libertação e as Ciências Sociais (DREHER, 2001).

\footnotetext{
5 Assinalamos a presença francesa, advinda de professores formados na Universidade de Estrasburgo em Les Sciences Religieuses, nos anos iniciais do curso na UMESP (MENDONÇA, 2007 apud MARQUES; ROCHA, 2007; CAMURÇA, 2011); A influência dos estudos de religião feita na Holanda na montagem do primeiro curso de CR na UFJF por Jaime Snoek (TEIXEIRA, 2012); Em 1989, a mudança de nomenclatura do curso para o singular na UFJF, sob orientação de Antônio Jose Guglielmi, demonstra também a influência da tradição alemã (Religionswissenschaft) (TEIXEIRA, 2012), que, no final da década de 1990, irá encontrar o seu maior expoente no país com a chegada de Frank Usarski na PUC-SP. Valle (2007) apud Marques e Rocha (2007), ainda aponta que, nas primeiras décadas do curso na PUC-SP, ele próprio esteve nos Estados Unidos para observar o funcionamento dos cursos de Study of Religion. Pelo que as evidências históricas apontam, não havia um total desconhecimento do que era feito fora do país nos anos iniciais das CR, porém que preocupações distintas norteavam as pesquisas aqui desenvolvidas.
} 
É sob esse prisma que podemos delinear a formação inicial das CR. Será a partir da fundação da Associação Nacional de Pesquisa em Teologia e Ciências da Religião (ANPTER), em 1995, refundada em 2008, com a sigla ANPTECRE, que se passou a conferir um maior fator de unidade à área ${ }^{6}$. Em resumo, não houve uma preocupação em traçar uma delimitação objetiva entre teologia e CR - o que geralmente aparece como um fator distintivo da tradição alemã (GRESCHAT, 2005) - nem a perspectiva de construção das CR como um campo do saber autônomo. Em razão disso, há a ausência de uma demarcação clara de métodos e de um objeto próprios às CR. Retomando as palavras de Mendonça (2007) apud Marques e Rocha (2007), parece não ter havido nenhuma ideia além das ditadas pelas circunstâncias, isto é, a de uma militância política e acadêmica em favor do estudo universitário do fenômeno religioso. Se há um grande pioneirismo nisso, que possibilitou a expansão dos estudos de religião no país, não só nas $\mathrm{CR}$, mas nas diversas disciplinas das humanidades, por outro lado, a falta de delimitação veio a produzir a incerteza identitária dos pesquisadores que se formam na área. O cientista da religião acaba retornado à especificidade de outras disciplinas e aos seus respectivos aparatos teóricos e metodológicos, como a Sociologia, Antropologia ou Psicologia da Religião ou mesmo a Teologia.

Nesse sentido, podemos falar de algumas ausências que são constitutivas da área: a) a de uma história do próprio campo de estudo; b) a definição do ofício do cientista da religião; c) a delimitação de um objeto e métodos que lhe sejam próprios. Esses problemas são anteriores a discussão epistemológica que se iniciou nos anos 2000. Os discursos que, na atualidade, disputam o estatuto científico das CR, reclamando uma paternidade teórica para o campo, não levam em consideração a conjuntura histórica que o fez emergir no Brasil. Esses impasses guardam uma estranha familiaridade com o que, no movimento da história e dos sentidos, foi silenciado, mas que retorna, pelo discurso, como uma disputa por significação.

Partimos do pressuposto de que a instância que marca o nó do problema se dá no âmbito discursivo, isto é, o do discurso científico das CR. Com o intuito de demonstrar isso, e passar para a análise de alguns textos em que poderemos

\footnotetext{
${ }^{6}$ É também nesse período que a influência da fenomenologia da religião começa a ganhar força nos programas de CR, não sendo ela parte do espetro constituinte da área, porém um direcionamento posterior (MENDONÇA, 2007; QUEIROZ, 2007 apud MARQUES; ROCHA, 2007).
} 
identificar o que afirmamos, cumpre fazer intervir em nosso percurso uma ciência do discurso a fim de compreender como circulam os sentidos que estão em disputa. Para isso, na próxima seção, apresentaremos a Análise de Discurso de linha francesa, nosso aporte teórico-analítico.

\section{A EPISTEMOLOGIA COMO LABORATÓRIO PARA UMA CIÊNCIA DO DISCURSO}

O discurso, sob o prisma da Análise do Discurso de linha francesa (doravante $\mathrm{AD}$ ), não se confunde com um objeto empírico, mas é entendido como uma rede de filiações sócio-históricas de identificação de sujeitos e sentidos, constituindo-se, simultaneamente, como um efeito dessas filiações e um trabalho de deslocamento sobre esse espaço (PÊCHEUX, 1997). No discurso, estabelece-se um espaço teórico em que convergem questões referentes à língua, a história e ao sujeito.

O ponto de partida dos trabalhos de Michel Pêcheux, fundador e principal expoente da disciplina, alinha-se à tradição francesa de história das ciências7, ocupando-se sobre a distinção entre o discurso científico e o discurso ideológico, a fim de entender como opera, na história das ciências, o corte epistemológico, isto é, o ponto sem regresso ${ }^{8}$ do qual uma ciência tem o seu começo (PÊCHEUX; BALIBAR, 1971).

Seguindo essa tradição, Canguilhem (1977) afirma que a prática discursiva das ciências é marcada pelas ideologias científicas, ou seja, "sistemas explicativos cujo o objeto é hiperbólico, relativamente à norma de cientificidade que eventualmente lhe é aplicada" (CANGUILHEM, 1977, p. 41). Uma ideologia científica não se confunde com uma falsa ciência ou superstição, trata-se, na verdade, de uma hipótese passível de ser demonstrada como verdadeira futuramente, precedendo sempre o campo em

\footnotetext{
7 Tendo em vista a proposta deste artigo, a nossa apresentação do projeto teórico de Pêcheux irá se centrar sobre a conexão entre seus trabalhos sobre a teoria do discurso e os pontos de intersecção que ele faz com a história das ciências, em especial pela relação que ele estabelece com a obra de um seus mentores, o filósofo Georges Canguilhem. Em outros trabalhos, é possível encontrar uma apresentação mais completa sobre o programa teórico-metodológico desenvolvido por Pêcheux e outros autores filiados a AD. Ver em especial Orlandi (2001) para uma abordagem introdutória. Para uma leitura mais aprofundada, conferir Pêcheux (2014).

8 O termo designa a tomada de posição descontinuísta em epistemologia e história das ciências, tendo como seus principais nomes Alexandre Koyré e Gaston Bachelard. Essa posição se caracteriza pela recusa a "noção de 'saber' como desenvolvimento contínuo do 'conhecimento comum' ao 'conhecimento científico', da aurora da ciência à ciência moderna” (PÊCHEUX; BALIBAR, 1971, p. 12).
} 
que uma ciência virá a se instituir. O discurso que a veicula, fundamenta a sua credibilidade no prestígio de uma ciência que a antecede e pelo estilo que dela procura imitar. A ideologia científica funciona como condição de possibilidade e obstáculo para a formação de uma ciência, existindo uma relação de sobreposição entre ideologia científica e o lugar que a ciência ocupará (CANGUILHEM, 1977). Em síntese, o estudo da epistemologia trabalha a articulação do registro da ideologia científica e do discurso científico, impedindo a redução da história de uma ciência a sua própria crônica, isto é, "um quadro sem sombras de relevo" (CANGUILHEM, 1977, p. 41).

Sob esse viés, Pêcheux (2014, p. 174) defenderá que não há discurso científico puro, pois "todo evento epistemológico (ruptura que inaugura uma ciência, uma 'descoberta' e produção de conhecimentos, 'reelaboração' etc.) se inscreve numa conjuntura historicamente determinada pelo estado das relações de desigualdadesubordinação”, não havendo, portanto, saber científico independente da ideologia e da história.

O objeto da história das ciências, para Canguilhem (1972), é dado pela historicidade do discurso científico, sob o interesse de compreender as condições de possibilidade que permitem esse discurso emergir. Ele se distingue do objeto científico, visto que esse último é constituído por um discurso metódico de uma ciência. Nas palavras do autor: "É a ciência que constitui seu objeto a partir do momento em que ela inventou um método para formar, por proposições capazes de ser compostas integralmente, uma teoria controlada pela inquietação de captá-la em erro" (CANGUILHEM, 1972, p. 15). Uma ciência em seu estado desenvolvido, segundo Pêcheux (2016a), irá se apresentar como um sistema em que objeto e método científico são homogêneos e articulados, sendo eles constituídos e aperfeiçoados mutuamente pelo desenvolvimento da prática científica:

Quer dizer que uma ciência nasce, de início, designando como pode seu objeto, e em seguida ela se desenvolve em torno dele: uma ciência em estado nascente é uma "aventura teórica" [...] o acesso ao objeto é obtido por caminhos ainda não trilhados, onde os passos em falso não estão excluídos (PÊCHEUX, 2016a, p. 47).

Pelo que precede, podemos afirmar que o discurso científico não é um objeto já dado para a história das ciências, mas cujo seu inacabamento lhe é essencial 
(CANGUILHEM, 1972). Ao que pode ser acrescentado, a história das ciências não tem sua relação circunscrita apenas com um conjunto de ciências sem coesão intrínseca, mas também com a não-ciência, com a ideologia e com a prática política e social.

Nesse sentido, a AD fornece importantes conceitos para compreender a constituição e circulação de sentidos no discurso científico, visto que ela se ocupa em investigar o funcionamento das diferentes materialidades discursivas, isto é, as condições verbais de existência dos objetos (científicos, estéticos, ideológicos, etc.) em uma conjuntura histórica dada (PÊCHEUX, 2016b). Isso permite interrogar os processos de construção de referência discursiva a fim de entender como a língua se inscreve na história para significar, produzindo os sentidos de um enunciado.

A referência discursiva de um enunciado é dada a partir das formações discursivas que combinam os seus efeitos em efeitos de interdiscurso. O conceito de formação discursiva permite estabelecer as regularidades no funcionamento do discurso, dito de outra forma, os domínios semânticos sob os quais as palavras adquirem seus sentidos, aquilo que, numa dada conjuntura, determina o que pode e deve ser dito, delimitando e regulando a ordem do dizer dos sujeitos (PÊCHEUX, 2014). Os dizeres que são capazes de serem enunciados pelo sujeito em uma formação discursiva são disponibilizados pelo interdiscurso, isto é, a rede de memórias que torna possível a perspectiva do dizível num processo discursivo:

O interdiscurso é todo o conjunto de formulações feitas e já esquecidas que determinam o que dizemos. Para que minhas palavras tenham sentido é preciso que elas já façam sentido. E isto é o efeito interdiscursivo: é preciso que o que foi dito por um sujeito específico, em um momento particular se apague na memória para que, passando para o "anonimato", possa fazer sentido em "minhas palavras" (ORLANDI, 2001, p. 33-34).

Em síntese, o interdiscurso designa o espaço discursivo e ideológico em que se desenvolvem as formações discursivas em função das relações de dominação, subordinação e contradição em uma dada conjuntura histórica (PÊCHEUX, 2014). Ele emerge nos discursos sob os efeitos de pré-construído - discursos que vieram de uma construção anterior, exterior e independente de um enunciado, mas que lhe fornecem sentido pela interpelação ideológica - e de discurso transverso - efeito de articulação e sustentação que atravessa e coloca em conexão os elementos discursivos 
constitutivos do pré-construído no enunciado9 (PÊCHEUX, 2014). São esses recortes do interdiscurso, em conjunto com as formações discursivas, que fazem com que uma palavra ou expressão não tenha um sentido em si mesmo, visto que “todo enunciado é intrinsecamente suscetível de torna-se outro, diferente de si mesmo, se deslocar discursivamente de seu sentido para um outro" (PÊCHEUX, 1997, p. 53), mas que ele seja sempre dado em referência à história e à ideologia na formulação do dizer.

Tendo até aqui exposto o arcabouço teórico que orienta o nosso estudo, passaremos, na próxima seção, ao delineamento metodológico que estrutura o gesto analítico sobre o corpus.

\section{PROCEDIMENTOS METODOLÓGICOS}

Para compor o corpus de análise, selecionamos dois artigos, um publicado na Revista Paralellus, em 2016, por Emerson Sena Silveira e o outro publicado na Revista Sacrilegens, em 2017, por Fábio Leandro Stern e Matheus Oliva da Costa. Os textos se propõem a discutir a questão metodológica das CR por vieses distintos.

O primeiro artigo parte do pressuposto de que há ambivalências metodológicas nas CR e propõe o politeísmo metodológico como uma saída para esse impasse. Ele argumenta que as ciências, na modernidade, foram marcadas por um monoteísmo metodológico, isto é, uma visão monoparadigmática na forma de se fazer ciência. Esse paradigma implicou em um fechamento das disciplinas dentro de suas próprias áreas. No caso das CR, esse fechamento resultou em tomar o religioso-sujeito em religioso-objeto. O politeísmo metodológico seria uma saída para os impasses gerados por essa perspectiva moderna nos estudos de religião (SILVEIRA, 2016).

$\mathrm{O}$ segundo artigo parte do argumento de que as CR possuem métodos próprios, propostos pela genealogia intelectual da área e que, no Brasil, em função de um desconhecimento da história internacional das $\mathrm{CR}$, haveria uma ideia equivocada de que faltam métodos para esse campo do saber. Os autores propõe uma revisão bibliográfica a partir dos pesquisadores que escreveram "dentro de genealogias

\footnotetext{
9 No decorrer da análise, teremos a ocasião de melhor detalhar o funcionamento desses conceitos. Em resumo, o pré-construído estabelece relações de equivalência entre palavras e classes, enquanto o discurso transverso ocorre a partir de uma relação de causa e consequência.
} 
intelectuais que trataram a ciência da religião enquanto área autônoma" (STERN; COSTA, 2017, p.72).

O nosso propósito é o de determinar como as palavras, expressões e enunciados funcionam no corpus selecionado com referentes ideológicos diferentes e, eventualmente, antagônicos. Temos como intuito compreender como os sentidos e os argumentos sobre a metodologia das CR emergem e circulam nesses discursos. Os recortes trazidos no corpus foram extraídos das considerações finais dos artigos, no momento em que os autores marcam seus posicionamentos sobre o assunto.

O pressuposto do qual partirmos é o de que as diferenças e contradições observadas no corpus não se situam no nível sintático ou lexical, mas nas formações discursivas que dominam os textos em seu conjunto, sendo identificáveis pela forma que o interdiscurso emerge como efeitos de pré-construídos e de discurso transverso. Nosso interesse se centrou nas características semântico-argumentativas dos enunciados e como elas operam sob esses mecanismos. As sequências discursivas selecionadas (com a abreviatura de SD) estão indicadas em negrito antes de sua apresentação e enumeradas cronologicamente. As marcações nelas feitas aparecerão em itálico.

\section{ANÁlISES EM CURSO: NO MOVIMENTO DOS SENTIDOS}

As três primeiras sequências foram extraídas do texto de Silveira (2016). No primeiro recorte, o autor sintetiza o diagnóstico feito durante o artigo do que seriam os principais problemas no campo teórico-metodológico das CR:

SD1 [...] identifico dois tipos de problemas na agenda de investigação das ciências da religião e que se estendem às ciências da cultura: a tendência à multiplicação de estudos sobrecarregados de empirismo, que esmaecem os estudos de maior fôlego hermenêutico, tornando a religião apenas um epifenômeno; $e$ a busca de essências abstratas, desconectadas dos corpos, das histórias e das políticas. Esses dois problemas são alimentados por outro: as imagens idealizadas da religião, do sujeito e sua subjetividade, da ciência e da razão moderna, desmontadas pelas práticas e linguagens discursivas críticas (SILVEIRA, 2016, p. 94 [grifos nossos]).

A crítica traçada nesse trecho (em relação ao empirismo, ao essencialismo e ao idealismo que marcariam os entendimentos da religião) é aplicada tanto as CR como 
às ciências culturais. Os dizeres de Silveira (2016) remetem à compreensão das CR como campo interdisciplinar, tanto pela crítica que é feita como pelo uso da nomenclatura no plural para designar a área (ciências da religião). A partir desses elementos podemos caracterizar a presença de uma formação discursiva interdisciplinar, visto que a regulação de sentidos que opera no discurso é a de que as são CR constituídas a partir de um enfoque interdisciplinar. A composição plural não é tida como um problema nessa formação discursiva, mas apontaria uma via para a superação dos impasses teóricos:

SD2 Com efeito, tendo a responder que é possível um politeísmo metodológico entendido como o não exclusivismo de uma perspectiva ou de um método, mas como abertura permanente aos caminhos científicos possíveis ou, na metáfora que aqui fabrico, pontes hermenêuticas. O manejo exímio e a aclimatação eficaz de teorias/metodologias oriundas de diásporas são fundamentais para as ciências da religião, assim como a atenção com o quadro teórico e com as mudanças epistemológicas vividas por outras ciências e campos do saber. [...] Para um politeísmo metodológico é preciso, então, uma antropologia focada nas sociedades complexas que traga outras formas de perceber o religioso e seus processos de desdiferenciação face à modernidade, ao observar a ação e a prática dos "cientistas nativos" ou dos "nativos-observadores", termos entendidos como construções provisórias e a posteriori (SILVEIRA, 2016, p. 94-95 [grifos nossos]).

Pela exposição do conceito de politeísmo metodológico, podemos observar os efeitos do interdiscurso trabalhando na composição de sentidos no texto em conjunto com a formação discursiva interdisciplinar a partir das duas adjetivações dadas ao termo (não exclusivismo de uma perspectiva ou de um método; abertura permanente aos caminhos científicos possíveis). No primeiro caso, podemos identificar o efeito de pré-construído, remetendo à memória de que as CR não são uma disciplina, mas um ponto de interseção das diferentes disciplinas que estudam o fenômeno religioso, o que faz trabalhar, no discurso, dois elementos presentes na constituição da memória da área no país: a) a tentativa de unificar sob um campo os estudos de religião; b) o intuito de produzir uma interlocução entre os pesquisadores das diferentes disciplinas das ciências humanas, tendo em vista a unidade sobre um mesmo objeto-tema. Essa memória fornece a condição de possibilidade para a defesa de uma abertura permanente aos caminhos científicos possíveis em CR. No segundo caso, estabelece-se um efeito de sustentação com a primeira proposição. A posição discursiva tomada no enunciado para a solução do impasse metodológico das CR se 
apoia na articulação entre o não exclusivismo metodológico e a abertura de pontes hermenêuticas. O discurso transverso que perpassa e sustenta o enunciado implicitamente, pode assim ser formulado: a condição para que se resolva o impasse metodológico das CR se dá pelo não exclusivismo metodológico e pela abertura de pontes hermenêuticas. Ou ainda: um método ou objeto que sejam pertinentes às CR indicam um não fechamento disciplinar.

Para o manejo (exímio) e a aclimatação (eficaz) do aparato teóricometodológico de outras disciplinas nas CR não é apresentado como isso deveria ser feito. Há uma presença-ausente no discurso: o seu lugar no enunciado está lá, no entanto o critério para a construção das pontes hermenêuticas não é dado (a atenção com o quadro teórico e com as mudanças epistemológicas vividas por outras ciências e campos do saber). O que é oferecido para preencher esse espaço é uma antropologia focada nas sociedades complexas. Na tentativa de delimitar a área, o autor volta-se à especificidade de uma disciplina. Essa antropologia que é proposta seria responsável por fornecer construções provisórias (teóricas) e a posteriori que regulariam o campo epistêmico das CR.

Se, por um lado, o politeísmo metodológico deixa em aberto a possibilidade de interlocução em CR para pesquisadores oriundos de diversas áreas, por outro, tornase impossível saber sob que identidade se ancora o pesquisador que se forma em CR. Isso faz retornar o problema da incerteza identitária do cientista da religião. Disso decorre um problema na proposta do autor que fica latente no recorte a seguir:

SD3 Proponho, assim, que a metodologia nas ciências da religião tenha como base um politeísmo metodológico que, ao invés de focalizar os objetos de estudo, tomando por dada a disciplina a partir da qual projeta seu foco investigativocognitivo, ela os submerge no campo (horizonte) de significações (e experiências multidimensionais). Dessa forma, haverá não um objeto pretensamente puro, incontaminado, mas um objeto-feito-tema, sendo revisto pelo viés do objeto e de seu estudo, revendo no mesmo movimento, o contexto em que se constroem as ciências da religião e o carro chefe temático, os fenômenos religiosos (SILVEIRA, 2016, p. 94 [grifos nossos]).

A tomada de posição nesse trecho produz uma contradição: no parágrafo anterior é dada a primazia de um determinado tipo de antropologia que deveria regular a construção de pontes hermenêuticas para, na sequência, o autor rejeitar o plano disciplinar, não tomando por dada a disciplina da qual parte seu foco 
investigativo-cognitivo. Outro problema que se apresenta intrincado a esse é sobre a construção do objeto das CR. Ele suspende focalizar os objetos de estudos à uma disciplina, contudo, no parágrafo anterior, ele mesmo lança mão de uma disciplina para, no parágrafo posterior, recuar na proposta. Aqui encontramos o impasse teórico central: um objeto científico sempre é dado em relação à uma ciência, ao passo que método e objeto constroem-se mutuamente numa ciência (CANGUILHEM, 1972; PÊCHEUX, 2016a). Dito isso, como pressupor um objeto de pesquisa sem um campo do saber no qual ele é projetado? É sob esse impasse que o artigo termina.

Já Stern e Costa (2017), propõe outra via para pensar a questão metodológica. Os autores partem da história internacional das CR a fim de afirmar a autonomia disciplinar e metodológica da área:

SD4 O presente estudo identificou uma série de métodos formulados por cientistas das religiões ao longo da história da sua disciplina [...] Ainda que muitos deles não sejam exclusivos da ciência da religião e derivem de fontes anteriores, isso não os invalida como construções de técnicas de pesquisa próprias da genealogia intelectual dessa área - até porque com outras ciências ocorre o mesmo. $O$ conhecimento dessa parte metodológica da identidade historicamente estabelecida pela ciência da religião reforça que essa ciência não se trata de uma mera "colcha de retalhos". Mesmo sendo plurimetodológica, a ciência da religião tem suas próprias regras de pesquisa (STERN; COSTA, 2017, p. 86 [grifos nossos]).

No recorte, a pluralidade das $\mathrm{CR}$ não é negada, mas é compreendida e organizada sob o viés da autonomia. Parte-se do pressuposto de que as CR são uma ciência autônoma e que tem o seu objeto próprio - por isso da nomenclatura no singular (ciência da religião). Tais elementos caracterizam a dominância de uma formação discursiva disciplinar regulando os sentidos dos enunciados. A pluralidade metodológica não é tomada como problema, embora também não seja apontada como solução para o impasse teórico da área. O que é posto em relevo é justamente a diferenciação das $\mathrm{CR}$ de outros campos disciplinares (Mesmo sendo plurimetodológica, a ciência da religião tem suas próprias regras de pesquisa). $\mathrm{O}$ direcionamento da metodologia seria dado por dois elementos que Stern e Costa (2017, p. 82-83) apresentaram no desenvolvimento do artigo: a abordagem ética, “a das categorias acadêmicas, fundamentadas nas teorias que permitem um exame analítico, com olhar que estuda as religiões de fora” e o agnosticismo metodológico "postura da ciência da religião de excluir de seus estudos a questão da verdade 
última”. Para eles, o problema seria um entendimento errôneo da própria disciplina no Brasil:

SD5 Entende-se que a ideia equivocada de que faltam métodos na ciência da religião pode ser resultado de muitas causas. Algumas possibilidades seriam: (1) uma falha no ensino dessa disciplina no Brasil, que pouco aborda em seus currículos a sua história internacional; (2) o fato da maioria dos docentes serem formados em outras áreas; e (3) seus pesquisadores em nível de pós-graduação geralmente derivarem de graduações que não a própria ciência da religião (STERN; COSTA, 2017, p. 86 [grifos nossos]).

Apesar dos autores apresentarem de forma tripartida os motivos desse engano, ele se articula sob dois elementos: a) que falta na área o ensino da história internacional da disciplina; b) a presença de docentes e pesquisadores terem suas formações em áreas distintas das CR. O discurso transverso que atravessa esses dizeres, dando-lhe sua sustentação pode ser posto da seguinte forma: A ideia equivocada que faltam métodos na ciência da religião indica um desconhecimento da história internacional da disciplina e que faltam docentes e pesquisadores com formação plena na área. O que está implícito nesse dizer é que para que ele produza sentido, as CR devem ser uma disciplina autônoma, homogênea.

No entanto, não é isso o que acontece no contexto brasileiro. A composição plural de pesquisadores (com a forte influência da Teologia da Libertação) e sua mobilização político-acadêmica é que permitiram o surgimento e institucionalização das CR. O adversário contra o qual a área teve que se defrontar não foi a teologia, como na Alemanha, porém a resistência na universidade brasileira à consolidação dos estudos de religião. Foi justamente a aliança entre a Teologia da Libertação e as Ciências Sociais que permitiu a entrada, de forma organizada, dos estudos de religião na academia, ainda que dela resulte os atuais impasses teóricos em que as CR se encontram no país. O posicionamento assumido pelos autores funciona como uma denegação, isto é, uma recusa em reconhecer os problemas epistemológicos que atravessam historicamente o campo no Brasil, silenciando-os, e propondo que a história que deve ser ensinada é a história internacional da disciplina. Outro elemento que fica implícito é o de que essa seria a verdadeira história. Ao serem expostas as sugestões para superar as causas que levariam a ideia equivocada da falta de metodologias, esses aspectos se tornam mais marcantes: 
SD6 Buscando superar isso, é sugerido que cientistas das religiões: (1) empoderemse da história própria da ciência da religião, saindo do conformismo de só conhecerem os autores e técnicas de suas áreas de formação original (no caso das pós-graduações), ou das áreas de formação de seus professores que não são cientistas das religiões de formação; e (2) que tenham mais coragem, ousadia e maior autonomia para desenvolver uma tradição de ciência da religião que não só repita, mas que também crie conhecimentos teóricos e metodológicos próprios, através de uma antropofagia intelectual que absorva as virtudes do saber internacional e o transforme criativamente, integrando-os aos nossos saberes e os adequando ao nosso contexto (STERN; COSTA, 2017, p. 86 [grifos nossos]).

Os autores reconhecem o problema da incerteza identitária, porém como decorrente de fatores (desconhecimento da história da disciplina e professores com formação em outras áreas) distintos dos elencados por Portella (2011), apresentados no início de nossa investigação (o resultado de entendimentos divergentes sobre o que seja a área e a falta de um consenso mínimo que estabeleça as bases comuns de um projeto acadêmico para as CR no Brasil).

Ao Stern e Costa (2017) sugerirem que os cientistas da religião empoderem-se da história própria da disciplina, a história é tão somente a redução da história de uma ciência a sua própria crônica (internacional), desarticulando o registro da ideologia científica (condições de possibilidade e obstáculos para a formação de uma ciência) e do discurso científico. Com isso, produz-se um efeito de que existe um discurso da ciência da religião que seria pretensamente puro, independente das relações históricas de desigualdade e subordinação com outras disciplinas. Essa posição, no entanto, é de frágil sustentação, posto que não há saber científico independente da ideologia e da história (CANGUILHEM, 1977; PÊCHEUX, 2016a). Isso compromete a proposta dos autores de que os cientistas da religião tenham maior autonomia para desenvolver uma tradição de ciência da religião e que absorva(m) as virtudes do saber internacional para que possam integrá-los aos nossos saberes e os adequando ao nosso contexto, visto que, para eles, não há uma história própria da área no Brasil que sirva de referência para a interlocução que é proposta. Disso derivam as seguintes questões: como propor uma antropofagia intelectual se essa intelectualidade só possui uma ideia equivocada do que ela própria seja, de sua área e de seus métodos e objeto de pesquisa? Como articular uma 
genealogia internacional da ciência da religião ao nosso contexto sem levar em consideração a constituição histórica da área no Brasil e suas especificidades?

\section{CONSIDERAÇÕES FINAIS}

Em nosso estudo, foi possível observar as relações de força e de sentidos que estão em concorrência na disputa pela paternidade teórica das CR. Para além das divergências entre as perspectivas interdisciplinar e disciplinar do campo, expressas nas formações discursivas, um ponto em comum entre os dois textos que compuseram o corpus de análise nos chamou a atenção: ambos silenciam a historicidade brasileira das CR em seus diagnósticos e propostas.

Longe de fornecer soluções para o impasse metodológico das CR, nosso estudo consistiu, sobretudo, em equacionar essa disputa a fim de abrir um novo horizonte de questões, em dar trabalho aos cientistas da religião no domínio da história nacional da área e as questões epistemológicas que a atravessam - sobre seus métodos, objeto e compreensões sobre o próprio campo de pesquisa.

Para isso, fizemos intervir outro domínio do saber: o da história das ciências e da análise de discurso, a fim de pensar o discurso científico e sua relação com a historicidade, trazendo para o debate o próprio discurso científico das CR como objeto de ausculta. Pretendemos, assim, fornecer condições de possibilidade para um estudo dos embates epistemológicos em Ciências da Religião e suas disputas por significação.

\section{REFERÊNCIAS}

ARAGÃO, Gilbraz de Souza. Encruzilhada dos estudos de religião no Brasil. Revista de Teologia e Ciências da Religião da Universidade Católica de Pernambuco. Recife, v. 5, n.1, p. 319-337, jul./dez. 2015. Disponível em: <http://www.unicap.br/ojs/index.php/theo/article/download/668/564>. Acesso em: 20 ago. 2017.

CAMURÇA, Marcelo. Ciências Sociais e Ciências da Religião: polêmicas e interlocuções. São Paulo: Paulinas, 2008.

CAMURÇA, Marcelo. Les Sciences Religieuses: um olhar a partir do Brasil para o campo de estudo das Ciências da Religião na França. Estudos de Religião, São 
Paulo, v. 25, n. 41, p. 12-28, jul./dez. 2011. Disponível em: $<$ https://www.metodista.br/revistas/revistasims/index.php/ER/article/view/2809/2775>. Acesso em: 10 dez. 2017.

CANGUILHEM, Georges. O objeto da história das ciências. Revista Tempo Brasileiro, Rio de Janeiro, n. 28, p. 7-21, jan./mar. 1972.

CANGUILHEM, Georges. Ideologia e Racionalidade nas Ciências da Vida. Lisboa: Edições 70, 1977.

DREHER, Luís. Ciência(s) da Religião: teoria e pós-graduação no Brasil. In: TEIXEIRA, Faustino. (Org.). A(s) Ciência(s) da Religião no Brasil. Afirmação de uma área acadêmica. São Paulo: Paulinas, 2001. p. 151-178.

FILORAMO, Giovanni; PRANDI, Carlo. As ciências das religiões. São Paulo: Paulus, 1999.

GRESCHAT, Hans-Jürgen. O que é ciência da religião? São Paulo: Paulinas, 2005 .

GROSS, Eduardo. A ciência da religião no Brasil: teses sobre sua constituição e seus desafios. In: OLIVEIRA, K. L.; REBLIN, I. A.; SCHAPER, V.G.; GROSS, E.; WESTHELLE, V. (Orgs.). Religião, política, poder e cultura na América Latina. São Leopoldo: Escola Superior de Teologia, 2012. p. 13-26.

MARQUES, Ângela Cristina Borges; ROCHA Marcelo. Memórias da fase inicial da Ciência da Religião no Brasil - Entrevistas com Edênio Valle, José J. Queiroz e Antonio Gouvêa Mendonça. REVER, São Paulo, p. 192-214, jan./mar. 2007. Disponível em: < pucsp.br/rever/rv1_2007/p_entrevista.pdf > . Acesso em: o1 mar. 2018.

MENDONÇA, Antônio Gouvêa. Ciências da Religião: do que mesmo estamos falando? Revista Ciências da Religião - História e Sociedade, São Paulo, v. 2, n. 2, p.16-34, 2004. Disponível em:

<editorarevistas.mackenzie.br/index.php/cr/article/view/2314/2163>. Acesso em: 30 nov. 2017.

ORLANDI, Eni Puccinelli. Análise de discurso: princípios e procedimentos. Campinas: Pontes, 2001.

PASSOS, João Décio; USARSKI, Frank. (Orgs.). Compêndio de ciência da religião. São Paulo: Paulinas/Paulus, 2013.

PÊCHEUX, Michel. Discurso: estrutura ou acontecimento. Campinas: Pontes, 1997.

PÊCHEUX, Michel. Semântica e discurso: uma crítica à afirmação do óbvio. Campinas: Editora da UNICAMP, 2014. 
PÊCHEUX, Michel. Reflexão sobre a situação teórica das ciências sociais e, especialmente, da Psicologia Social. In: ORLANDI, Eni Puccinelli. (Org.). Análise de Discurso: Michel Pêcheux: Textos escolhidos por Eni Puccinelli Orlandi. Campinas: Pontes Editores, 2016. p. 21-54.

PÊCHEUX, Michel. Metáfora e interdiscurso. In: ORLANDI, Eni Puccinelli. (Org.). Análise de Discurso: Michel Pêcheux. Textos escolhidos por Eni Puccinelli Orlandi. Campinas: Pontes Editores, 2016. p. 151-161.

PÊCHEUX, Michel; BALIBAR, Étienne. Definições. In: PÊCHEUX, Michel; FICHANT, Michel. Sobre a História das Ciências. Lisboa: Editorial Estampa, 1971. p. 11-16.

PORTELLA, Rodrigo. Reflexos no Espelho: Reflexão sobre as Ciência(s) da(s) Religião(ões) nos programas de pós-graduação brasileiros. Revista Brasileira de História das Religiões, ANPUH, v. 3, n. 9, p. 211-227, jan./abr. 2011. Disponível em: <http://www.dhi.uem.br/gtreligiao/pdf8/10.pdf. >. Acesso em: 20 abr. 2017.

USARSKI, Frank. Os Enganos sobre o Sagrado - Uma Síntese da Crítica ao Ramo Clássica da Fenomenologia e seus Conceitos-Chaves. REVER, São Paulo, v. 4, n. 4, p. 73-95, out./dez. 2004. Disponível em:

<www.pucsp.br/rever/rv4_2004/p_usarski.pdf>. Acesso em: 25 fev. 2018.

USARSKI, Frank. Constituintes da ciência da religião. Cinco ensaios em prol de uma disciplina autônoma. São Paulo: Paulinas, 2006.

USARSKI, Frank. (Org.). O espectro disciplinar da Ciência da Religião. São Paulo: Paulinas, 2007. p. 9-15.

SENRA, Flávio. Estudos de Ciência(s) da(s) Religião(ões) e Teologia no Brasil:

Situação atual e perspectivas. REVER, São Paulo, v. 15, p. 196-214, jan./jun. 2015. Disponível em:

<https://revistas.pucsp.br/index.php/rever/article/view/26196/18859>. Acesso em: o2 mar. 2018.

SILVEIRA, Emerson José Sena da. Uma metodologia para as Ciências da Religião? Impasses metodológicos e novas possibilidades hermenêuticas. Paralellus: Revista de Estudos da Religião da UNICAP, Recife, v. 7, n. 14, p. 73-98, jan./abr. 2016. Disponível em: <www.unicap.br/ojs/index.php/paralellus/article/view/672/856>. Acesso em: 04 dez. 2017.

SILVEIRA, Emerson José Sena da.; MORAES JR, Manoel Ribeiro de. A Dimensão Teórica dos Estudos da Religião: horizontes histórico, epistemológico e metodológico nas Ciências da Religião. São Paulo: Fonte Editorial, 2017.

STARK, Rodney; BAINBRIDGE, Wiliams Sims. Uma teoria da Religião. São Paulo: Paulinas, 2008. 
STERN, Fábio; COSTA, Matheus Oliva da. Metodologias desenvolvidas pela genealogia intelectual da ciência da religião. Sacrilegens, v. 14, n.1, p. 70-89, jul./dez. 2017. Disponível em: <www.ufjf.br/sacrilegens/files/2017/12/14-1-6.pdf>. Acesso em: 25 fev. 2018.

PIEPER, Frederico Pires. Ciência(s) da(s) Religião(ões). In: JUNQUEIRA, Sergio; BRANDENBURG, Laude; KLEIN, Remi. (Org.). Compêndio de Ensino Religioso. São Leopoldo/Petrópolis: Sinodal/Vozes, 2017. p. 131-138.

TEIXEIRA, Faustino. (Org.). A(s) Ciência(s) da Religião no Brasil. Afirmação de uma área acadêmica. São Paulo: Paulinas, 2001. p. 297-322.

TEIXEIRA, Faustino. O processo da gênese da(s) ciência(s) da religião na UFJF. Numen, v. 15, n.2, p. 537-550, jul./dez. 2012. Disponível em: $<$ https://numen.ufjf.emnuvens.com.br/numen/article/view/2008/1459>. Acesso em: 06 mar. 2018. 